\title{
Synthesis and characterization of epoxy resins from fast pyrolysis bio-oil
}

1 Mehul Barde MSc

PhD candidate, Center for Polymers and Advanced Composites, Auburn University, Auburn, AL, USA; Department of Chemical Engineering, Auburn University, Auburn, AL, USA (Orcid:0000-0001-5886-4504)

2 Sushil Adhikari PhD

Professor, Department of Biosystems Engineering, Auburn University, Auburn, AL, USA
3 Brian K. Via PhD

Professor, Forest Products Development Center, Auburn University, Auburn, AL, USA

$4 \quad$ Maria L. Auad PhD

Professor, Center for Polymers and Advanced Composites, Auburn University, Auburn, AL, USA; Department of Chemical Engineering, Auburn University, Auburn, AL, USA (corresponding author: auad@auburn.edu)
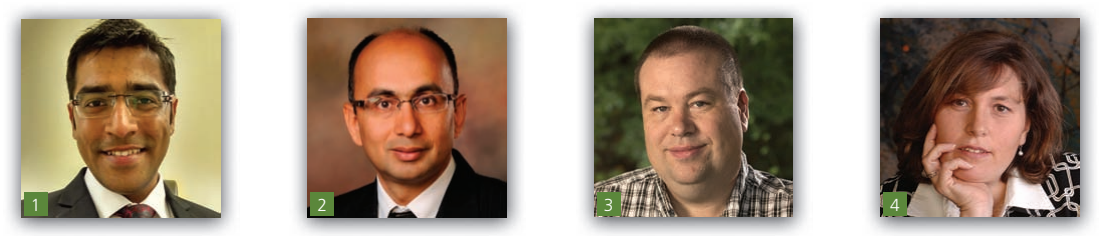

Fast pyrolysis bio-oil was used to replace phenol up to $50 \mathrm{wt} \%$ to synthesize bionovolac resin. A glycidylation reaction was employed for epoxidizing novolac, bionovolac, fast pyrolysis bio-oil and $\alpha$-resorcylic acid. Gas chromatography-mass spectroscopy was used to observe available compounds in the bio-oil, whereas Fourier transform infrared and phosphorus-31 $\left({ }^{31} \mathrm{P}\right)$ nuclear magnetic resonance techniques were used for the characterization of the resulting resins. Epoxy resins were cross-linked by polyaddition reaction with the polyetheramine hardener Jeffamine T-403 at elevated temperatures. The thermal and thermomechanical properties of cured thermosets were measured by differential scanning calorimetry and dynamic mechanical analysis, respectively. The glass transition temperatures and moduli of novolac-based cross-linked systems were found to be superior to those of epoxy resins without novolacs. Additionally, Soxhlet extraction and scanning electron microscopy were performed to characterize solvent resistance and morphology, respectively. The incorporation of $\alpha$-resorcylic acid-based epoxy enhanced the properties of cured polymers. The preparation of bio-based epoxy-novolac thermoset networks resulted in reduced consumption of petroleum-based chemicals.

\section{Notation}

$E^{\prime} \quad$ storage modulus

$h_{\mathrm{i}} \quad$ peak height, initial

$h_{t} \quad$ peak height at time $t$

$M \% \quad$ mass retained

$M_{\mathrm{f}} \quad$ mass of dried solids

$M_{\mathrm{i}} \quad$ initial mass of solids

$N \quad$ normality of hydrogen bromide-glacial acetic acid solution

$n \quad$ active chains density

$R \quad$ universal gas constant

$T$ temperature

$T_{\mathrm{g}} \quad$ glass transition temperature

$V \quad$ volume of hydrogen bromide-acetic acid solution

$W_{\mathrm{E}} \quad$ amount of epoxy resins

$W_{\mathrm{J}} \quad$ required amount of Jeffamine T-403

$w \quad$ weight of the sample

$x_{t} \quad$ extent of conversion

\section{Introduction}

Epoxy resins are important thermosetting polymers due to their versatile applications in coatings, adhesives, composites and the electronics industry. ${ }^{1}$ General characteristics such as aromatic structures and macromolecular network formation after cross-linking offer excellent chemical, mechanical and electrical properties to epoxy systems. ${ }^{2}$ Using novolac resin as a precursor of epoxy resins has been a great choice as it improves the thermomechanical performance of epoxies due to higher hydroxyl $(\mathrm{OH})$ functionality and additional properties of novolac polymers. ${ }^{3}$ Novolac resins are traditionally made by reacting phenol and formaldehyde with a molar excess of phenol over formaldehyde in acidic medium. With a strong aromatic backbone, they offer high solvent, heat and water resistance. They possess enhanced thermal properties, mechanical performance and good dimensional stability. ${ }^{4,5}$ Nevertheless, all epoxy and epoxidized novolac (EN) resins commercially utilized are derived from petrochemicals. Concerns over petroleum resources have caused a greater need for technological advances in biomass conversion. Specific types of biomass-derived compounds such as plant oils have been used for synthesizing epoxy monomers and polymers. ${ }^{6-8}$ Historically, plant biomass was often used to deliver energy by direct combustion processes, but this method provided limited energy due to the heating value of plant biomass being lower than those of other petroleum-based fuels. ${ }^{9}$ Over a long period of time, plant and animal biomass had been converted to fossil 
fuels by natural processes. Although there are several challenges to biorefining of plant biomass in an efficient manner, ${ }^{10}$ thermochemical transformations such as fast pyrolysis have been successful in producing a mixture of diverse functional organic compounds. ${ }^{9,11,12}$ This mixture is termed as bio-oil and generally contains oxygenated aliphatic and aromatic hydrocarbons. ${ }^{13}$ Reactive functional groups of organic compounds can be derivatized to produce monomers or oligomers, which can further be polymerized to yield polymers. Since pyrolysis and liquefaction can be often used to break down lignin along with cellulose and hemicellulose, monophenols or oligophenolic structures can be found in the liquid bio-oil. Phenol derivatives from bio-oil have been used in several ways to produce phenol-formaldehyde polymeric materials. ${ }^{14-16}$ Biomass-based phenolic foams were prepared by $\mathrm{Li}$ et al. ${ }^{17}$ by using hydrolysis lignin depolymerized by a low-temperature and low-pressure method. $\operatorname{Pan}^{18}$ synthesized novolac and resol-type phenol-formaldehyde polymers from organic solvent-liquefied biomass. Similar approaches for the production of epoxides from bio-oil and biomass have been well documented. The pyrolysis of loblolly pine was carried out by Celikbag et al., ${ }^{19}$ and the subsequent bio-oil was substituted in conventional epoxy resin formulations before catalyzing with triphenylphosphine. It was found that the bio-oil had good compatibility with epoxy resin and was able to process thermoset materials with a high glass transition temperature and cross-linking density. ${ }^{19}$ In another attempt of successful replacement, an acetone-treated blend of bio-oil and epoxy resin was reacted with diethylenetriamine hardener. ${ }^{20}$ The bioderived substituent component was obtained from a liquefaction process by changing several parameters. ${ }^{18}$ Wood liquefied with polyethylene glycol/glycerol and sulfuric acid $\left(\mathrm{H}_{2} \mathrm{SO}_{4}\right),{ }^{21,22}$ ozonepretreated wood liquefied with polyethylene glycol/glycerol and sulfuric acid ${ }^{23}$ and bagasse liquefied with ethylene carbonate ${ }^{24}$ were blended with epoxy resins and were cured to yield cross-linked epoxies. A recent study enlightens the synthesis of epoxy resins from deconstructed softwood lignin. ${ }^{25}$ Sibaja $^{26}$ and Celikbag et al..$^{27}$ carried out direct glycidylation of biomass pyrolysis oil and biomass liquefaction oil, respectively. In the present work, the authors used fast pyrolysis bio-oil as a raw material to synthesize prepolymeric epoxy, novolac and EN resins. The resins were also blended with a previously studied epoxy oligomer produced from $\alpha$-resorcylic acid to observe the effect of low-viscosity and low-molecular-weight epoxide on the final properties. The resulting resins can be aimed as replacements for traditional epoxy matrices in composite applications and as binders in coatings and adhesives. These resins can be cross-linked with hardeners to build high-performance thermosetting networks. Cross-linked bio-thermosets in this study were also compared to cross-linked traditional thermosets.

\section{Materials and methods}

\subsection{Materials}

Fast pyrolysis bio-oil derived from hardwood was obtained from Red Arrow, USA. Phenol (detached crystals, 99\%), formalin solution $(37 \% \mathrm{w} / \mathrm{w})$, acetone, methanol, sodium hydroxide, ( \pm -epichlorohydrin (99\%), 3,5-dihydroxybenzoic acid ( $\alpha$-resorcylic acid), chromium (III) acetyl acetonate, $N$-hydroxy-5-norbornene-2,3dicarboximide (NHND) and deuterated chloroform were purchased from VWR International, USA. 2-Chloro-4,4,5,5-tetramethyl-1,3,2dioxaphospholane (TMDP) was ordered from Sigma-Aldrich. Oxalic acid, anhydrous, was supplied by Spectrum Chemical Mfg. Corp. Benzyltriethylammonium chloride was obtained from TCI. Epon 828, an epoxy resin based on bisphenol A, was provided by Momentive, USA. Jeffamine T-403, a polyetheramine-based epoxy hardener, was ordered from Huntsman, USA.

\subsection{Methods}

\subsubsection{Characterization of fast pyrolysis bio-oil}

The fast pyrolyis bio-oil had some water content, which was removed by a rotary evaporator at $60^{\circ} \mathrm{C}$ under reduced pressure. The bio-oil was qualitatively analyzed by gas chromatography-mass spectroscopy (GC-MS) as per the procedure reported elsewhere. ${ }^{28}$ Around $0.5 \mathrm{~g}$ of bio-oil was diluted with $12 \mathrm{ml}$ of methanol and mixed well. A split ratio of 20:1 was set for injecting $1 \mu \mathrm{l}$ of diluted bio-oil into a DB-1701 column equipped to an Agilent $7890 \mathrm{GC} /$ 5975 MS.

Phosphorus-31 $\left({ }^{31} \mathrm{P}\right)$ nuclear magnetic resonance (NMR) was used to measure the hydroxyl number and quantify different categories of hydroxyl groups present in the bio-oil using the phosphitylation procedure. ${ }^{29}$ The stock solution was prepared by dissolving $20 \mathrm{mg}$ of NHND and $20 \mathrm{mg}$ of chromium (III) acetyl acetonate in the mixture of $3 \mathrm{ml}$ pyridine and $2 \mathrm{ml}$ deuterated chloroform. To the preweighed bio-oil amount (approximately $20 \mathrm{mg}$ ), $550 \mu \mathrm{l}$ of stock solution was added, and the vial was stirred. TMDP $(150 \mu l)$ was added to the mixture, and the vial was stirred well to make sure that no precipitates were formed. The sample was transferred to the NMR tube, and the spectrum was acquired with a Bruker Avance II $250 \mathrm{MHz}$ spectrometer using an inverse-gated decoupling pulse sequence, a $90^{\circ}$ pulse angle, a $25 \mathrm{~s}$ pulse delay and 128 scans.

Fourier transform infrared (FTIR) spectroscopy was performed with attenuated total reflection method using a Thermo Scientific Nicolet 6700 FTIR spectrophotometer and Omnic 7.3 software. The spectra were collected in the wave number range $400-4000 \mathrm{~cm}^{-1}$ at a resolution of $4 \mathrm{~cm}^{-1}$ and 40 scans. The same parameters were used for collecting FTIR spectra of all materials discussed henceforth.

\subsubsection{Synthesis of novolac and bionovolac resins}

Novolac resin was synthesized as per the procedure described in the literature $^{30}$ Phenol was used in molar excess $(1: 0 \cdot 8)$ compared to formaldehyde. Phenol and oxalic acid ( 0.0522 per mol of phenol) were added to the reaction flask, and the temperature was raised to $90^{\circ} \mathrm{C}$. Formaldehyde aqueous solution (formalin, 37\%) was added dropwise to the reaction mixture under stirring. The reaction was continued at $90^{\circ} \mathrm{C}$ for the next $3 \mathrm{~h}$. Bionovolac resin was synthesized by the same procedure, replacing phenol with bio-oil by $50 \mathrm{wt} \%$. The progress of reaction was monitored by FTIR spectroscopy. The hydroxyl number of the novolac and bionovolac resins was measured by phosphorus$31 \mathrm{NMR}$ as per the procedure mentioned in the previous section. 


\subsubsection{Synthesis of epoxy resins}

Epoxy resins were synthesized from four different phenolic substrates - that is, bio-oil, novolac, bionovolac and $\alpha$-resorcylic acid. A two-step glycidylation method reported in the literature was followed. $^{31,32}$ The desired amount of the phenolic monomer was taken in a glass reactor, and epichlorohydrin equivalent to $4 \mathrm{M}$ equivalents (eq)/hydroxyl was added to it. The temperature was raised to $100^{\circ} \mathrm{C}$ while stirring continuously and benzyltriethylammonium chloride $\left(\mathrm{BnEt}_{3} \mathrm{NCl}\right)$, a phase transfer catalyst, was added $(0 \cdot 012 \mathrm{M}$ eq/hydroxyl). The reaction was carried out for $1 \mathrm{~h}$ at $100^{\circ} \mathrm{C}$, and then the temperature was allowed to fall to $30^{\circ} \mathrm{C}$. In the second step, a mixture of benzyltriethylammonium chloride ( $0.012 \mathrm{M}$ eq/hydroxyl $)$ and $20 \mathrm{wt} \%$ aqueous solution of sodium hydroxide ( $2 \mathrm{M}$ eq/hydroxyl) was added dropwise to the reaction mixture maintained at $30^{\circ} \mathrm{C}$ while stirring. After the addition was completed, the reaction was continued for $90 \mathrm{~min}$ at $30^{\circ} \mathrm{C}$. The organic layer was washed several times with water to remove salt. Unreacted epichlorohydrin that might be present in the organic layer was distilled off by rotary evaporation under reduced pressure and at $90^{\circ} \mathrm{C}$. Epoxy resins were named as epoxidized bio-oil (EBO), EN, epoxidized bionovolac (EBN) and glycidyl 3,5-diglycidoxybenzoate (GDGB). Phosphorus-31 NMR spectra of EBO, EN and EBN were collected as per the method described earlier in this study. The stepwise synthesis of epoxy resins is described in Figure 1.

\subsubsection{Measurement of epoxy equivalent weight}

Epoxy resins were analyzed by FTIR and the epoxy equivalent weight (EEW) was measured by the hydrogen bromide $(\mathrm{HBr})$-glacial acetic acid solution method. Around $0 \cdot 3-0 \cdot 4 \mathrm{~g}$ of sample was taken in a $50 \mathrm{ml}$ Erlenmeyer flask, and $10 \mathrm{ml}$ acetone

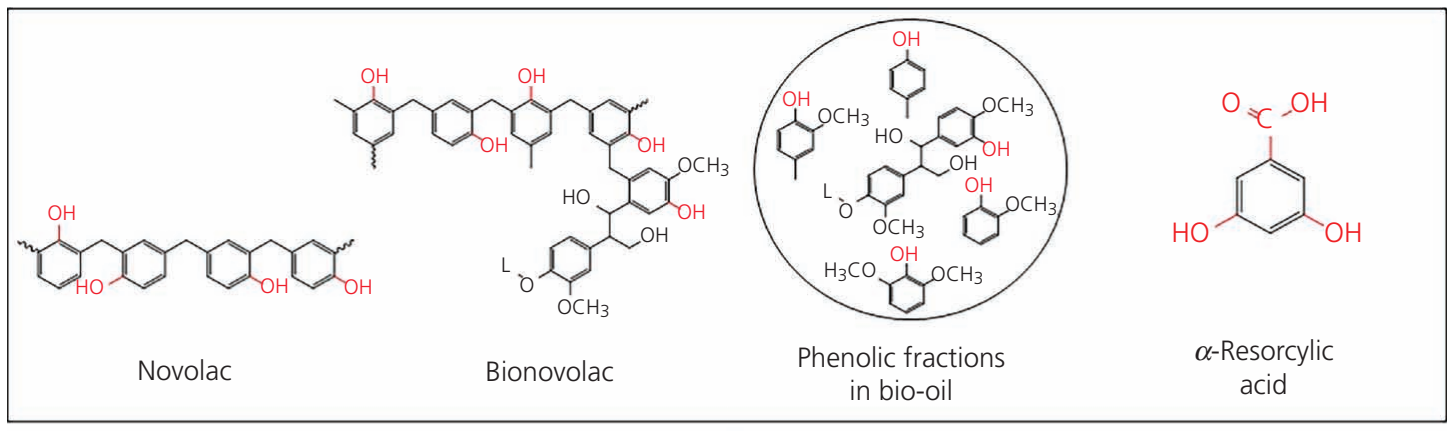

(a)

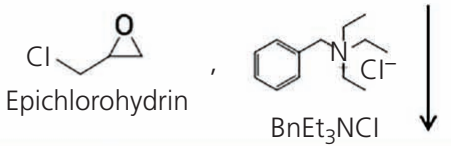

$100^{\circ} \mathrm{C}$

$60 \mathrm{~min}$

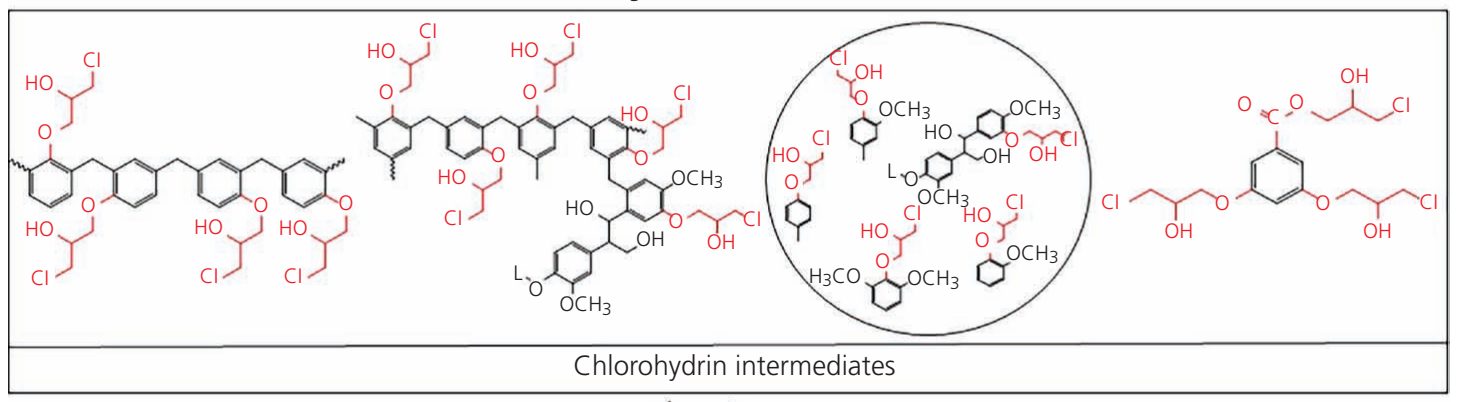

(b)

$30^{\circ} \mathrm{C}$,

$90 \mathrm{~min}$

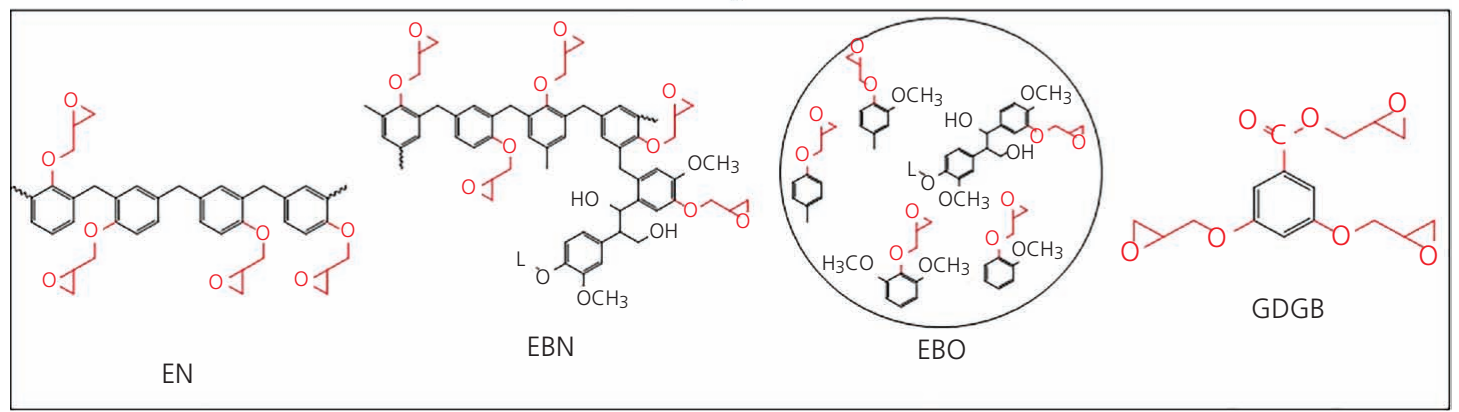

Figure 1. Glycidylation of phenolic substrates 
was added to it. The contents of the flask were stirred well so as to dissolve the epoxy sample in acetone. Just before the titration, a drop of crystal violet indicator solution $(1 \mathrm{~g} / 1$, in glacial acetic acid) was added, and the contents were titrated with $0.1 \mathrm{~N}$ hydrogen bromide-glacial acetic acid solution until the end point 'blue-green color' persisted for $30 \mathrm{~s}$. In the case of dark-colored resins, the end point was observed under flash light. The EEW was calculated as per the following formula.

$$
\text { 1. } \mathrm{EEW}=\frac{1000 \times w}{N \times V}
$$

where $w$ is the weight of the sample; $N$ is the normality of hydrogen bromide-glacial acetic acid solution; and $V$ is the volume of hydrogen bromide-glacial acetic acid solution required to titrate the sample.

\subsubsection{Cross-linking of epoxy resins}

Epoxy resins and their physical blends were mixed with a calculated amount of Jeffamine T-403. The following equation was used for calculating the required amount of Jeffamine T- $403, W_{\mathrm{J}}$.

2. $W_{\mathrm{J}}=\frac{W_{\mathrm{E}}}{\mathrm{EEW}} \times \mathrm{AHEW}$

where $W_{\mathrm{E}}$ is the amount of epoxy resin; AHEW is the amine hydrogen equivalent weight, the weight of amine hardener containing one equivalent of amine hydrogen.

All resin mixtures were added to polytetrafluoroethylene (PTFE) molds and heated in conventional oven at $60^{\circ} \mathrm{C}$ for $2 \mathrm{~h}$ followed by $80,90,100,120$ and $140^{\circ} \mathrm{C}$ for $1 \mathrm{~h}$ each and finally at $165^{\circ} \mathrm{C}$ for $15 \mathrm{~min}$.

\subsubsection{Evaluation of thermomechanical performance}

In dynamic mechanical analysis (DMA), an oscillating strain is applied on a sample while increasing the temperature, and the dynamic mechanical moduli are measured. The modulus is a complex quantity of which the real part is the storage modulus, whereas the complex part is the loss modulus. The storage modulus corresponds to the energy stored elastically, while the loss modulus indicates the characteristic energy lost by way of heat. ${ }^{33}$ The ratio of loss modulus to storage modulus is termed as $\tan \delta$, the maximum of which is generally considered as the glass transition temperature of the polymeric system. Viscoelastic regions and the glass transition temperature of the cross-linked systems can be evaluated using DMA. In the current study, three-point bending geometry was used using a TA Instruments RSA III dynamic mechanical analyzer, on the samples with approximate dimensions of $25 \times 10 \times 3 \mathrm{~mm}^{3}$. The constant strain of $0 \cdot 1 \%$ and cyclic frequency of $1 \mathrm{~Hz}$ was applied while increasing the temperature from 25 to $200^{\circ} \mathrm{C}$ at $10^{\circ} \mathrm{C} / \mathrm{min}$. Storage moduli and $\tan \delta$ were plotted against temperature, and the glass transition temperature was measured at the maximum $\tan \delta$. The active chains density $n$ was calculated by the following formula.
3. $n=\frac{E^{\prime}}{3 R T}$

where $E^{\prime}$ is the storage modulus $(\mathrm{Pa})$ at the temperature $T$; and $T$ is the glass transition temperature +50 expressed in kelvins; and $R$ is the universal gas constant $(8 \cdot 314 \mathrm{~J} \mathrm{~mol} / \mathrm{K})$.

Differential scanning calorimetry (DSC) was used to observe the glass transition temperature of the cross-linked polymer networks by using a heat-cool-heat temperature program.

\subsubsection{Other techniques}

Soxhlet extraction was carried out with $200 \mathrm{ml}$ dichloromethane (continuously refluxed) for $24 \mathrm{~h}$. After extraction, the residual solids were dried and weighed. Mass retained (M\%) was calculated by the following equation.

4. $M \%=\frac{M_{\mathrm{f}}}{M_{\mathrm{i}}} \times 100$

where $M_{\mathrm{f}}$ is the mass of dried solids after extraction and $M_{\mathrm{i}}$ is the initial mass of solids.

Cross-linked thermoset systems were analyzed under a scanning electron microscope. The samples were immersed in liquid nitrogen and then cut to observe the cross-sections. All samples were sputter-coated with gold before scanning electron microscopy (SEM) analysis.

\section{Results and discussion}

\subsection{Characterization of fast pyrolysis bio-oil}

Using GC-MS, it was observed that the bio-oil consisted of substituted phenols, carboxylic acids, hydroxyaldhydes, hydroxyketones, alcohols and monosaccharides. The total hydroxyl content of bio-oil measured by phosphorus-31 NMR was $5.80 \mathrm{mmol}$ hydroxyl/g. Figure 2 depicts the phosphorus-31 NMR spectrum of the bio-oil with the types and quantities of the hydroxyl groups.

\subsection{Characterization of bionovolac resins}

The FTIR analysis of both novolac and bionovolac resins confirmed the appearance of peaks at $3300-3200 \mathrm{~cm}^{-1}(\mathrm{O}-\mathrm{H}$ stretch), $3013 \mathrm{~cm}^{-1}$ ( $\mathrm{sp}^{2} \mathrm{C}-\mathrm{H}$ stretch), $1612-1435 \mathrm{~cm}^{-1}$ (aromatic $\mathrm{C}=\mathrm{C}$ stretch), $1229 \mathrm{~cm}^{-1}$ (phenolic $\mathrm{C}-\mathrm{O}$ stretch) and $755 \mathrm{~cm}^{-1}$ (aromatic C-H, out-of-plane bend). It indicated that the synthesis of bionovolac resin followed a reaction pathway similar to that of a novolac resin. The decreasing intensity of the peaks with increasing bio-oil content is attributable to the reduction in the total phenolic content of bio-oil/phenol blend. The bio-oil is not only composed of substituted phenols but also contains many other organic compounds. The formation of the phenol-formaldehyde network 


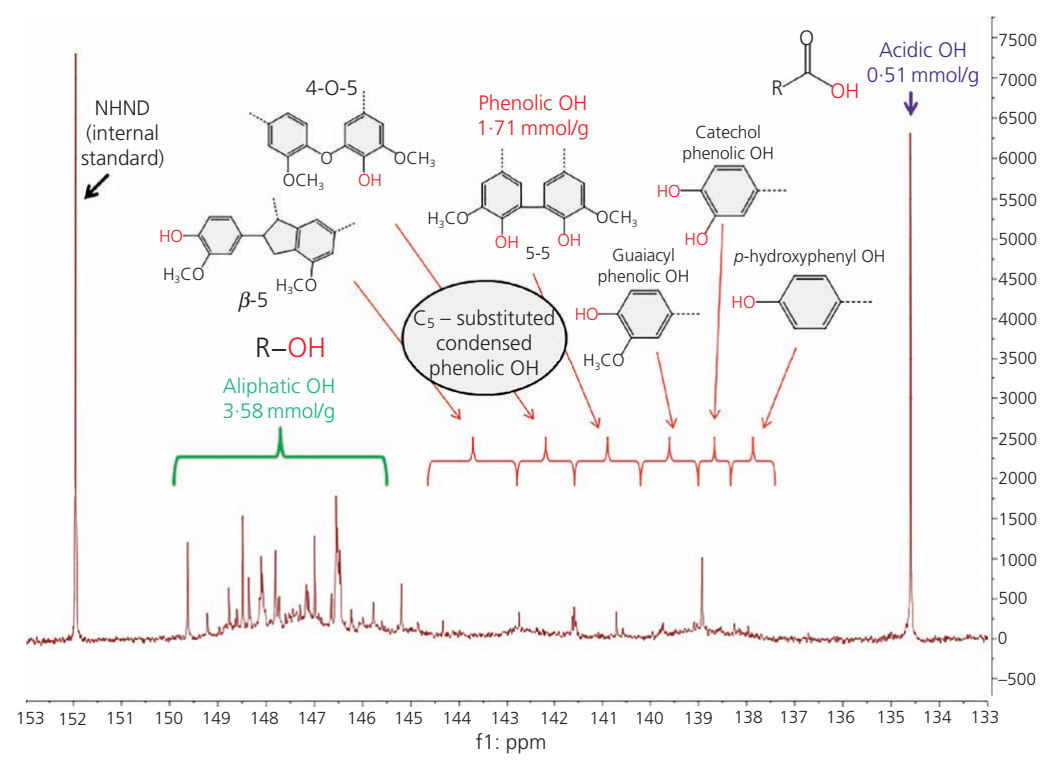

Figure 2. Phosphorus-31 NMR characterization of bio-oil

was carried out by the selective reaction of formaldehyde at the ortho and para sites of phenol and substituted phenols. The progress of the reaction of novolac and bionovolac was observed using a peak at $755 \mathrm{~cm}^{-1}$ that reflects the aromatic $\mathrm{C}-\mathrm{H}$ out-ofplane vibration band. The intensity of the peak reduced with time due to the formation of $\mathrm{C}-\mathrm{C}$ bond at ortho/para positions. The extent of conversion of phenolic monomers $x_{t}$ is calculated by the formula reported in the literature. ${ }^{34}$

5. $x_{t}=\left(1-\frac{h_{t}}{h_{\mathrm{i}}}\right) \times 100$ where $h_{t}$ is the height of $755 \mathrm{~cm}^{-1}$ peak at time $t$ and $h_{\mathrm{i}}$ is the height of $755 \mathrm{~cm}^{-1}$ peak at time 0 .

\subsection{Characterization of epoxy resins}

Figure 3 shows identifiable differences between epoxy resins and their phenolic precursors. The peaks observed in the range 906-911 $\mathrm{cm}^{-1}$ appear due to the asymmetric bending of the epoxide ring, whereas the peaks ranging between 835 and $845 \mathrm{~cm}^{-1}$ are due to symmetric bending. Similarly, deformation peaks were observed for $\mathrm{C}-\mathrm{O}-\mathrm{C}$ in the range $1225-1250 \mathrm{~cm}^{-1}$ and in the range $1026-1043 \mathrm{~cm}^{-1}$ for asymmetric and symmetric

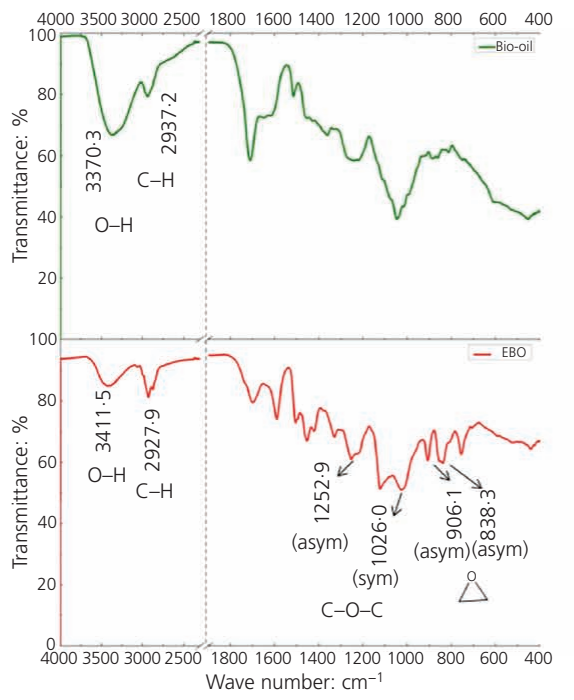

(a)

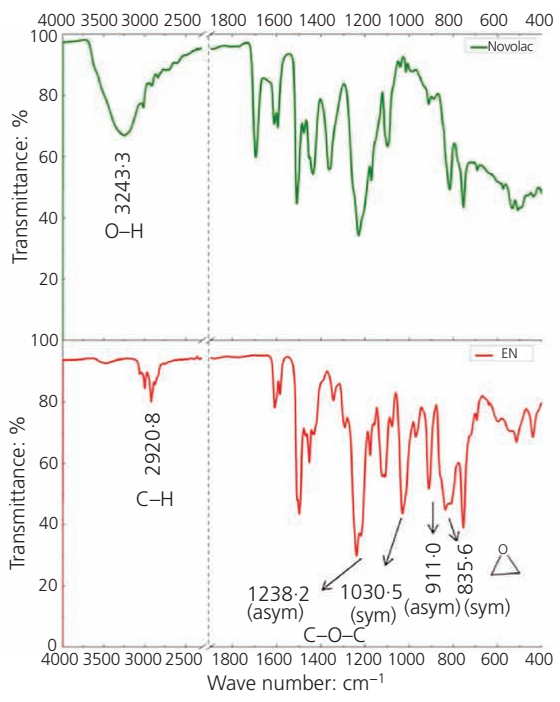

(b)

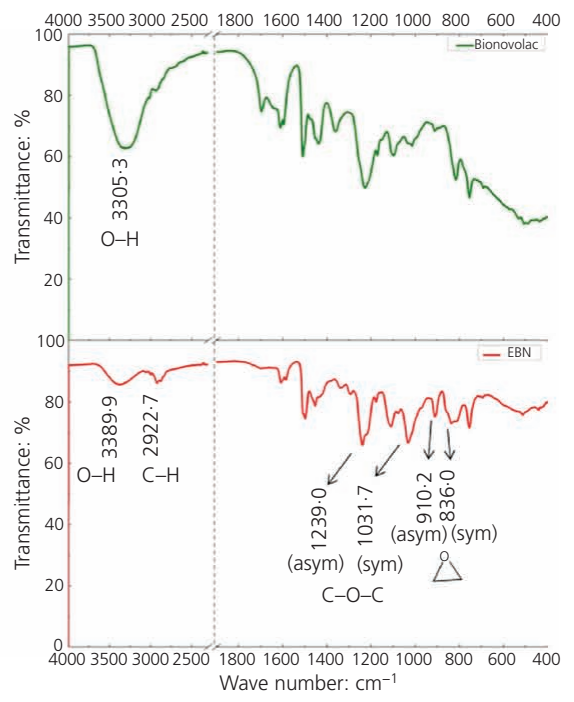

(c)

Figure 3. FTIR spectra of (a) bio-oil and EBO, (b) novolac and EN and (c) bionovolac and EBN. asym, asymmetric; sym, symmetric 
Table 1. Hydroxyl numbers measured by phosphorus-31 NMR for (a) bio-oil and EBO, (b) novolac and EN and (c) bionovolac EBN

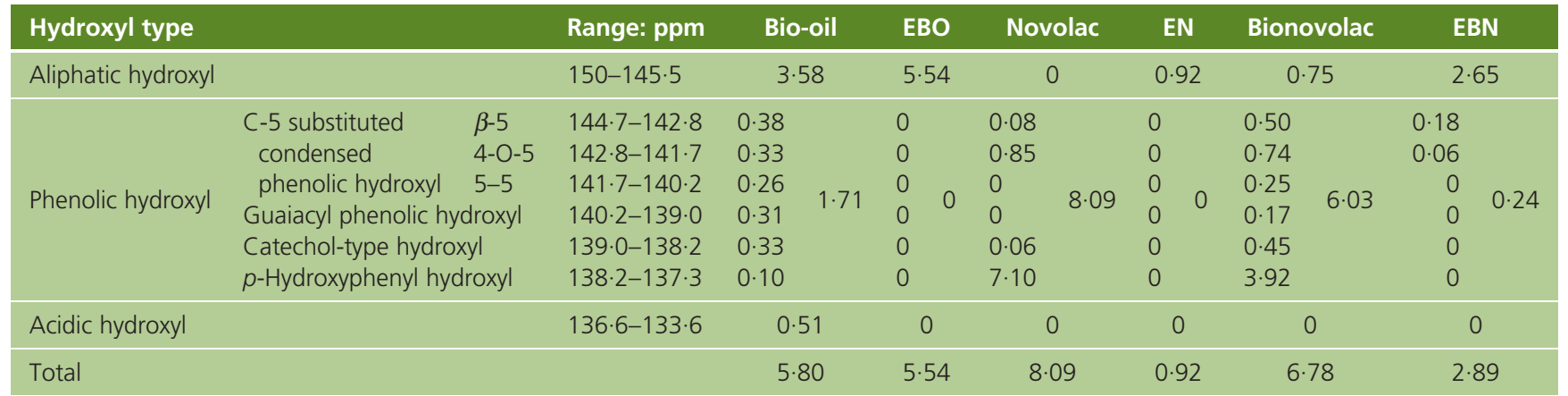

ppm, parts per million

bendings, respectively. A broad peak in the range $3100-3500 \mathrm{~cm}^{-1}$ corresponding to $\mathrm{O}-\mathrm{H}$ stretching vibrations was observed to reduce in every case. This is due to the conversion of phenolic hydroxyl and carboxyl hydroxyl groups into glycidyl functionality. Aliphatic hydroxyl, however, tends to appear due to low reactivity during epoxidation.

The conversion of phenolic hydroxyl groups was confirmed by phosphorus-31 NMR as depicted in Table 1. In all cases, different phenolic groups were successfully epoxidized, although EBN shows residual phenolic hydroxyl content for $\beta-5$ and 4-O-5 type phenolic hydroxyl. The aliphatic hydroxyl content was observed to increase in each epoxy resin. This is due to the ring opening of epoxy groups to form secondary aliphatic hydroxyl groups. Acidic hydroxyl groups were absent in novolac and bionovolac resins because of the purification performed before the epoxidation reaction. Bio-oil, however, was used as it was and, hence, consisted of carboxylic acids, which also took part in epoxidation. It can be proved from the zero acidic hydroxyl content of EBO.

The EEWs of epoxy resins are listed in Table 2. An epoxy resin derived from a compound containing a higher amount of phenolic and carboxyl hydroxyl groups is more likely to have a higher number of epoxides after the epoxidation reaction. Thus, a higher amount of epoxides tends to show less EEW. Novolac and bionovolac are prepolymers, while bio-oil is a mixture of monomeric, oligomeric and macromolecular phenolic components. Due to the high phenolic hydroxyl content, EN showed an EEW lower than those of EBN and EBO. The EEW of EBN was higher than that of EBO since EBN is a prepolymer and probably has a high molecular weight. The reason that GDGB displayed the lowest EEW is that its precursor, $\alpha$-resorcylic acid, is a low-molecular-weight monomer bearing three hydroxyl groups per molecule (one carboxyl and two

Table 2. EEWs of epoxy resins

\begin{tabular}{ll} 
Epoxy resin & EEW: g/eq \\
\hline EN & $132 \pm 2$ \\
EBN & $326 \pm 6$ \\
EBO & $314 \pm 2$ \\
Epoxy resin from $\alpha$-resorcylic acid (GDGB) & $107 \pm 3$ \\
Epon 828 (a commercial epoxy resin) & $158 \pm 3$
\end{tabular}

phenolic hydroxyls), all of which have a tendency to be converted into epoxides. Epon 828 is a commercially manufactured epoxy resin and is generally made to have the desired EEW.

\subsection{Thermomechanical performance of epoxy resins and other techniques}

In the case of DMA, the temperature at which $\tan \delta$ achieved the maximum value was taken as the glass transition temperature, while for DSC, the temperature at maximum decline in the slope of heat flow against temperature was considered. The measured values of glass transition temperature, storage modulus at room temperature, active chain density and mass retained (Soxhlet extraction) are listed in Table 3. Figures 4 and 5 depict the plots of heat flow and storage moduli of cross-linked thermosets, respectively.

It was observed that the epoxy resins derived from phenolformaldehyde prepolymers (novolac and EBN) showed higher performance than epoxy resin based only on bio-oil. At the molecular level, novolac and bionovolac resins consist of a continuous network of phenolic compounds bridged by methylene groups, whereas EBO contains monomeric and oligomeric epoxide compounds with lignin fractions. Epoxidized phenolformaldehyde resins retain the macromolecular aromatic network after epoxidation and, hence, display properties better than those of EBO. Moreover, the incorporation of GDGB helped enhance the properties of EBN due to the higher epoxide content of GDGB. All epoxy resins derived from bio-oil, directly or indirectly, showed a glass transition temperature higher than that of commercially used epoxy resin Epon 828, despite its higher epoxide content. The lignin fractions available in bio-oil form a part of the molecular structure of the bio-oil-derived epoxy resins and offer additional strength to the network. The active chain density was found to be lower in the case of bio-oil-derived epoxy resins compared to their petroleum-derived counterparts. The lower value of active chain density is impacted by lower modulus at elevated temperature, which probably was due to the poor thermal stability of lignin fractions at elevated temperatures. A similar effect was reflected by the mass (\%) retained during Soxhlet extraction. The morphology of cured epoxy resins was found to be comparable as seen in Figure 6. All cured samples 
Table 3. Thermomechanical properties of epoxy resins

\begin{tabular}{|c|c|c|c|c|c|c|}
\hline Epoxy resin & Notes & $\begin{array}{l}T_{\mathrm{g}}, \mathrm{DMA} \\
{ }^{\circ} \mathrm{C}\end{array}$ & $\begin{array}{c}T_{\mathrm{g}}, \text { DSC: } \\
{ }^{\circ} \mathrm{C}\end{array}$ & $\begin{array}{c}E^{\prime} \text { at room } \\
\text { temperature: } \mathrm{GPa}\end{array}$ & $\begin{array}{c}\text { Active chains' } \\
\text { density, } n: \mathrm{mol} / \mathrm{m}^{3}\end{array}$ & $\begin{array}{l}\text { Mass } \\
\text { retained: } \%\end{array}$ \\
\hline EN & Not made from bio-oil & 127 & 119 & 1.68 & 5321 & $99 \cdot 8$ \\
\hline EBN & & 91 & 89 & $2 \cdot 00$ & 1855 & $90 \cdot 5$ \\
\hline $\begin{array}{l}\text { EBN:GDGB } \\
50: 50\end{array}$ & $\begin{array}{l}\text { 50:50 (wt\%) physical blend of EBN and } \\
\text { GDGB, cross-linked by Jeffamine T-403 }\end{array}$ & 99 & 102 & $2 \cdot 80$ & 4665 & $96 \cdot 5$ \\
\hline Epon 828 & $\begin{array}{l}\text { A commercial epoxy resin based on bisphenol } \\
\text { A, cured by Jeffamine T-403 }\end{array}$ & 80 & 76 & $1 \cdot 77$ & 2599 & 99 \\
\hline EBO & & 92 & 89 & 1.88 & 404 & 77 \\
\hline
\end{tabular}

indicated similar homogeneity. The fractured surface of EN suggested high brittleness, whereas EBO revealed the low extent of brittleness. Moreover, the fractured surface of EBN is indicative of a more diverse system due to the possibility of the

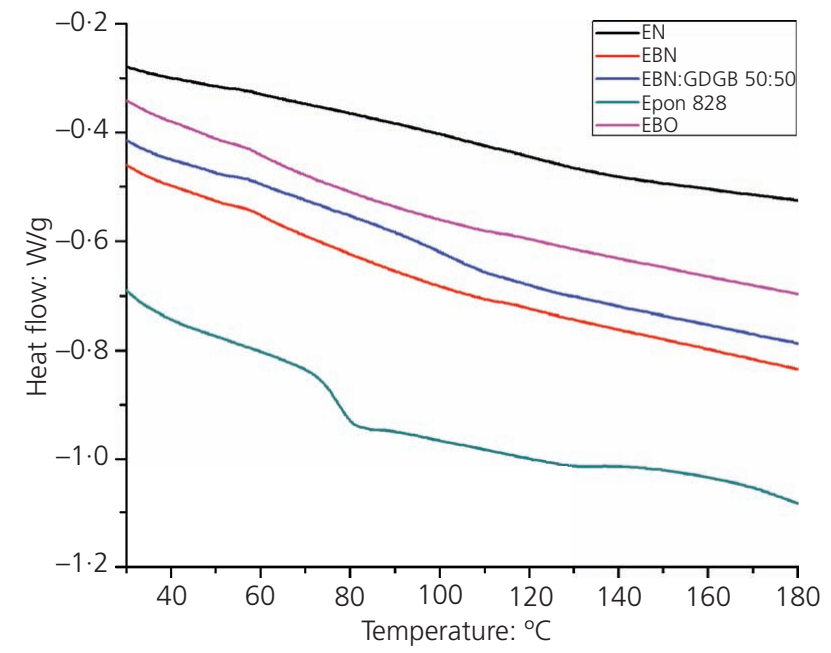

Figure 4. DSC analysis of cross-linked thermosets

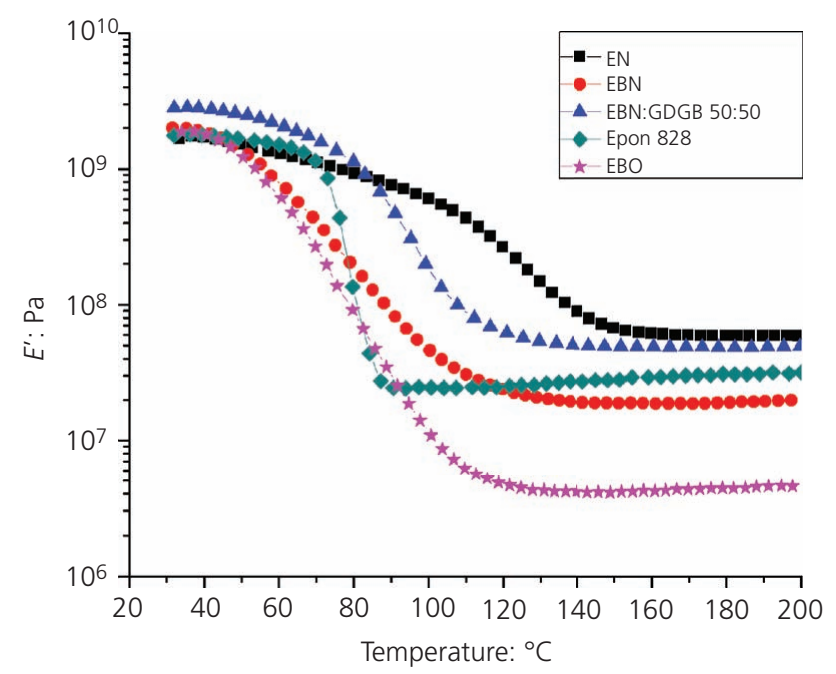

Figure 5. DMA analysis of cross-linked thermosets formation of bionovolac from several aromatic substituted compounds. The incorporation of GDGB to EBN had an effect on increasing the overall homogeneity of the system due to reduced complexity. It was found that resins derived from phenolformaldehyde networks had higher brittle lines, indicating more brittleness of the cured systems.

\section{Conclusion}

The phenolic hydroxyl and carboxylic functional groups in the bioderived compounds can be functionalized to epoxides. Bio-oil proves to be a potential phenolic resource and can be epoxidized directly or by synthesizing its novolac-type prepolymer. Bio-oilbased epoxy resins have structural and chemical similarities with petroleum-derived ones and can also be cross-linked by the existing amine hardeners. The synthesis of novolac-type prepolymer followed by epoxidation helps achieve properties of epoxy and novolac resins. The synthesized resin systems yielded thermoset materials with high glass transition temperatures and high moduli, despite having higher biocontent and more uncontrolled, complex chemistry than traditional epoxy resins. The compatibility of bio-oil-based epoxy resin with nonbio-oil-based resin (GDGB) helped to achieve homogeneity of the final thermosets. This phenomenon was also confirmed by SEM, which revealed that the morphologies of bio-oil-based epoxies are comparable to those of their petrochemical-based analogs. As the bio-oil-based epoxy polymers performed on par with the phenol- and bisphenol A-based epoxides, they can be a potential replacement in many applications such as matrices for composites, resins for coatings and adhesives and so on. Further, the fact that the bio-oil can be sourced from any lignocellulosic biomass can open a whole new category of raw materials including, but not limited to, energy crops, forest waste, sawdust, agricultural waste and so on. The utilization of such resources would help reduce the consumption of petrochemicals and achieve higher sustainability.

\section{Acknowledgements}

The authors would like to acknowledge the US Department of Agriculture-National Institute of Food and Agriculture (USDANIFA-2015-67021-22842) and National Science Foundation-Centers of Research Excellence in Science and Technology's Center of Excellence in Nano-Bio Materials derived from Biorenewable and Waste Resources for funding this study. Additionally, this work 
Synthesis and characterization of epoxy resins from fast pyrolysis bio-oil Barde, Adhikari, Via and Auad

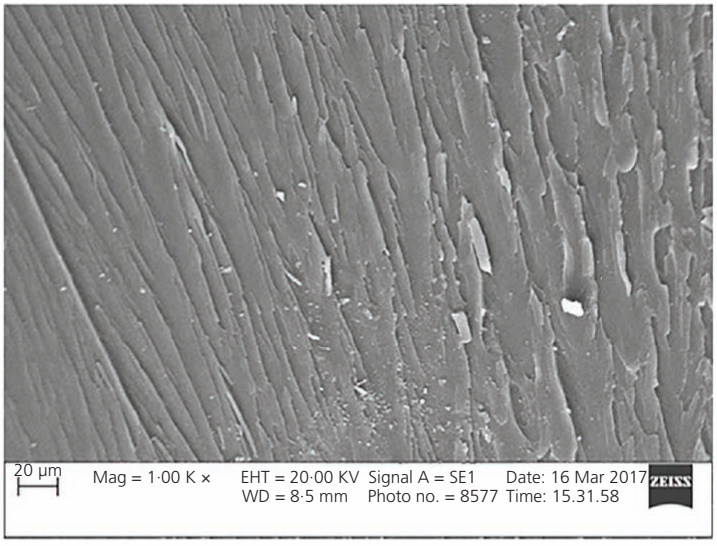

(a)

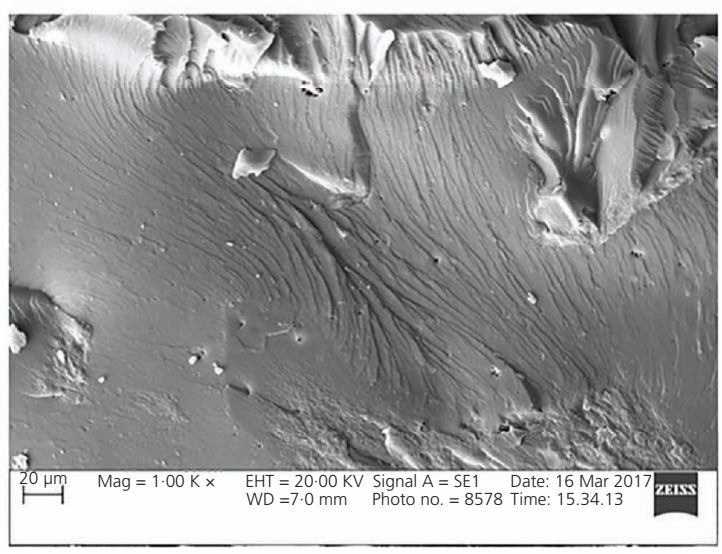

(c)

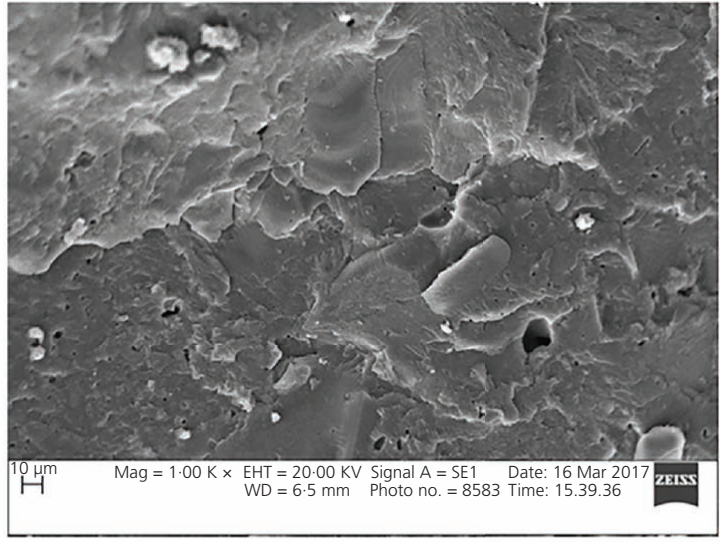

(b)

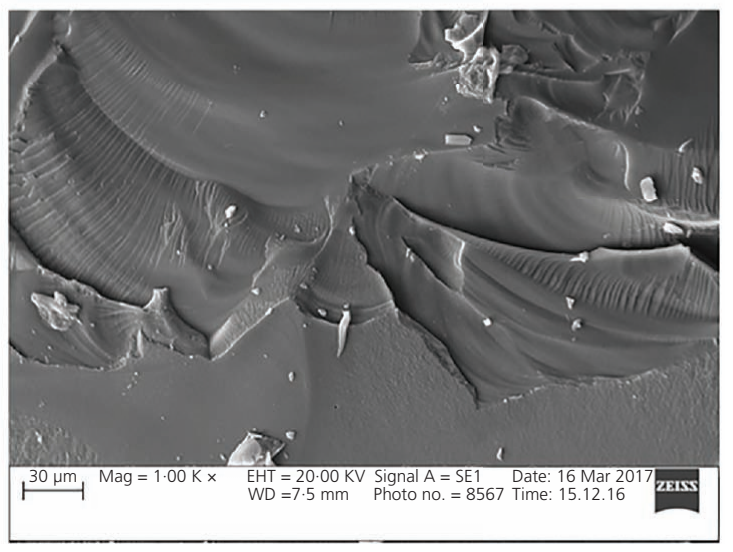

(d)

Figure 6. SEM photographs of cross-linked thermosets: (a) EN, (b) EBN, (c) EBN:GDGB 50:50 and (d) EBO

was supported by the Agriculture and Food Research Initiative 'Hydrophobic Bio-Oil-Epoxy Binders for Wood Composites' (project award number 2017-67021-26134).

\section{REFERENCES}

1. Ellis B (1993) Introduction to the chemistry, synthesis, manufacture and characterization of epoxy resins. In Chemistry and Technology of Epoxy Resins, 1st edn. (Ellis B (ed.)). Chapman \& Hall London, UK, pp. $1-35$

2. Ogata M, Kinjo N and Kawata T (1993) Effects of crosslinking on physical properties of phenol-formaldehyde novolac cured epoxy resins. Journal of Applied Polymer Science 48(4): 583-601.

3. Gour RS, Raut KG and Badiger MV (2017) Flexible epoxy novolac coatings: use of cardanol-based flexibilizers. Journal of Applied Polymer Science 134(23): 1-12.

4. Nair CPR (2004) Advances in addition-cure phenolic resins. Progress in Polymer Science 29(5): 401-498.

5. Knop A and Pilato LA (1985) Phenolic Resins: Chemistry, Applications and Performance. Springer, Berlin, Germany.

6. Yang GZ, Rohde BJ and Robertson ML (2013) Hydrolytic degradation and thermal properties of epoxy resins derived from soybean oil. Green Materials 1(2): 125-134, https://doi.org/10.1680/gmat.12.00023.

7. Maiorana A, Ren LY, Lo Re G et al. (2015) Bio-based epoxy resin toughening with cashew nut shell liquid-derived resin. Green Materials 3(3): 80-92, https://doi.org/10.1680/jgrma.15.00019.
8. Kim JR and Sharma S (2012) The development and comparison of bio-thermoset plastics from epoxidized plant oils. Industrial Crops and Products 36(1): 485-499.

9. Bridgwater AV, Meier D and Radlein D (1999) An overview of fast pyrolysis of biomass. Organic Geochemistry 30(12): 1479-1493.

10. Ragauskas AJ, Williams CK, Davison BH et al. (2006) The path forward for biofuels and biomaterials. Science 311(5760): 484-489.

11. Bridgwater AV (2012) Review of fast pyrolysis of biomass and product upgrading. Biomass \& Bioenergy 38: 68-94.

12. Peterson AA, Vogel F, Lachance RP et al. (2008) Thermochemical biofuel production in hydrothermal media: a review of sub- and supercritical water technologies. Energy \& Environmental Science 1(1): $32-65$.

13. Stas M, Kubicka D, Chudoba J and Pospisil M (2014) Overview of analytical methods used for chemical characterization of pyrolysis bio-oil. Energy \& Fuels 28(1): 385-402.

14. Effendi A, Gerhauser H and Bridgwater AV (2008) Production of renewable phenolic resins by thermochemical conversion of biomass: a review. Renewable \& Sustainable Energy Reviews 12(8): 2092-2116.

15. Vithanage $A E$, Chowdhury E, Alejo LD et al. (2017) Renewably sourced phenolic resins from lignin bio-oil. Journal of Applied Polymer Science 134(19): 1-10.

16. Kelley SS, Wang XM, Myers MD, Johnson DK and Scahill JW (1997) Use of biomass pyrolysis oils for preparation of modified phenol formaldehyde resins. In Developments in Thermochemical Biomass 
Synthesis and characterization of epoxy

resins from fast pyrolysis bio-oil

Barde, Adhikari, Via and Auad
Conversion (Bridgwater AV and Boocock DGB (eds)). Springer, Dordrecht, the Netherlands, pp. 557-574.

17. Li B, Wang Y, Mahmood N et al. (2017) Preparation of bio-based phenol formaldehyde foams using depolymerized hydrolysis lignin. Industrial Crops and Products 97: 409-416.

18. Pan H (2011) Synthesis of polymers from organic solvent liquefied biomass: a review. Renewable \& Sustainable Energy Reviews 15(7): 3454-3463.

19. Celikbag Y, Robinson TJ, Via BK, Adhikari S and Auad ML (2015) Pyrolysis oil substituted epoxy resin: improved ratio optimization and crosslinking efficiency. Journal of Applied Polymer Science 132(28): $1-9$.

20. Liu Y, Via BK, Pan YF et al. (2017) Preparation and characterization of epoxy resin cross-linked with high wood pyrolysis bio-oil substitution by acetone pretreatment. Polymers 9(3): 1-14.

21. Kobayashi M, Tukamoto K and Tomita B (2000) Application of liquefied wood to a new resin system-synthesis and properties of liquefied wood/epoxy resins. Holzforschung 54(1): 93-97.

22. Kobayashi M, Hatano $Y$ and Tomita B (2001) Viscoelastic properties of liquefied wood/epoxy resin and its bond strength. Holzforschung 55(6): 667-671.

23. Asano T, Kobayashi M, Tomita B and Kajiyama M (2007) Syntheses and properties of liquefied products of ozone treated wood/epoxy resins having high wood contents. Holzforschung 61(1): 14-18.

24. Xie T and Chen FG (2005) Fast liquefaction of bagasse in ethylene carbonate and preparation of epoxy resin from the liquefied product. Journal of Applied Polymer Science 98(5): 1961-1968.
25. van de Pas DJ and Torr KM (2017) Biobased epoxy resins from deconstructed native softwood lignin. Biomacromolecules 18(8): 2640-2648.

26. Sibaja BH (2016) Thermosetting Polymers from Renewable Resources. PhD thesis, Auburn University, Auburn, AL, USA.

27. Celikbag Y, Meadows S, Barde M et al. (2017) Synthesis and characterization of bio-oil-based self-curing epoxy resin. Industrial \& Engineering Chemistry Research 56(33): 9389-9400.

28. Shakya R, Whelen J, Adhikari S, Mahadevan R and Neupane S (2015) Effect of temperature and $\mathrm{Na}_{2} \mathrm{CO}_{3}$ catalyst on hydrothermal liquefaction of algae. Algal Research 12: 80-90.

29. Ben HX and Ragauskas AJ (2011) NMR characterization of pyrolysis oils from Kraft lignin. Energy \& Fuels 25(5): 2322-2332.

30. Zhang $G$ and Choi W (2012) A low-cost sensitizer based on a phenolic resin for charge-transfer type photocatalysts working under visible light. Chemical Communications 48(86): 10621-10623.

31. Aouf C, Benyahya S, Esnouf A et al. (2014) Tara tannins as phenolic precursors of thermosetting epoxy resins. European Polymer Journal 55: 186-198.

32. Aouf C, Le Guerneve C, Caillol S and Fulcrand H (2013) Study of the O-glycidylation of natural phenolic compounds: the relationship between the phenolic structure and the reaction mechanism. Tetrahedron 69(4): 1345-1353.

33. Sperling LH (2006) Introduction to Physical Polymer Science. Wiley, Hoboken, NJ, USA.

34. Poljansek I and Krajnc M (2005) Characterization of phenolformaldehyde prepolymer resins by in line FT-IR spectroscopy. Acta Chimica Slovenica 52(3): 238-244.

\section{How can you contribute?}

To discuss this paper, please submit up to 500 words to the journal office at journals@ice.org.uk. Your contribution will be forwarded to the author(s) for a reply and, if considered appropriate by the editor-in-chief, it will be published as a discussion in a future issue of the journal.

ICE Science journals rely entirely on contributions from the field of materials science and engineering. Information about how to submit your paper online is available at www.icevirtuallibrary.com/page/authors, where you will also find detailed author guidelines. 